\title{
EDITORIAL
}

\section{Targeting bone metastases starting from the preneoplastic niche: home sweet home}

\author{
Daniele Santini"*, Bruno Vincenzi', Francesco Pantano', Giuseppe Tonini' and Francesco Bertoldo² \\ See related review by Clézardin, http://breast-cancer-research.com/content/13/2/207
}

\begin{abstract}
The metastatic process is a multistep coordinated event with a high degree of efficiency. Specific subpopulations of cancer stem cells, with tumorinitiating and migratory capacity, can selectively migrate towards sites that are able to promote survival and/or proliferation of metastatic tumor cells through a microenvironment modification. Cross-talk between the bone microenvironment and cancer cells can facilitate bone tropism of cancer cells. Fully understanding this complexity represents a major challenge in anti-cancer research and a mandatory step towards the development of new drugs potentially able not only to reduce the consequences of bone lesions but also to target the metastatic process in visceral sites.
\end{abstract}

Philippe Clezardin in his original and complete review masterfully describes the bone metastasis process [1]. It seems to share many analogies with a famous fairy tale:

\section{'Once upon a time a very poor woodcutter lived in a tiny cottage in the forest with his two children, Hansel and Gretel. His second wife often ill-treated the children and was forever nagging the woodcutter. "There is not enough food in the house for us all. There are too many mouths to feed! We must get rid of the two brats," she declared' [2].}

The determinants of 'successful' metastatic growth in a given organ (for example, bone marrow) are not completely understood, but there is a clear evidence to suggest

*Correspondence: d.santini@unicampus.it

'Department of Medical Oncology, University Campus Bio-Medico, Via Alvaro del Portillo 200, 00128, Rome, Italy

Full list of author information is available at the end of the article that tumor cells and host tissue both play important roles in the metastatic process. This model is based on experimental data evaluating cancer stem-like cells, a population of cells within a tumor mass able to leave the primary tumor mass and navigate through the bloodstream to localize in new sites where the 'soil' can exert an important role on their fate [3,4]. For this reason, premetastatic niches are thought to be fertile regions of tissue that facilitate the invasion, survival and/or proliferation of metastatic tumor cells, providing a highly novel mechanism for the promotion of metastasis [5]. Moreover, chemokines are small chemo-attractant cytokines that bind to specific G-protein-coupled transmembrane receptors present on the plasma membranes of target cells. These molecules can guide circulating cancer cells to the bone. So we can postulate that crosstalk between the bone microenvironment and cancer cells can facilitate bone tropism of cancers cells.

$$
\begin{aligned}
& \text { 'On [Hansel and Gretel] walked and walked, till } \\
& \text { suddenly they came upon a strange cottage in the } \\
& \text { middle of a glade. "This is chocolate!" gasped } \\
& \text { Hansel as he broke a lump of plaster from the wall. } \\
& \text { "And this is icing!" exclaimed Gretel, putting } \\
& \text { another piece of wall in her mouth. Starving but } \\
& \text { delighted, the children began to eat pieces of candy } \\
& \text { broken off the cottage. "Isn't this delicious?" said } \\
& \text { Gretel, with her mouth full. She had never tasted } \\
& \text { anything so nice.' }
\end{aligned}
$$

We still do not know whether cancer cells already possess an osteomimetic phenotype when they detach from the primary tumor, or whether these characteristics are instead acquired when they colonize the bone niche. There is evidence that some cancer cells need a biological signature to invade bone [6]. Many molecules are produced from cancer cells invading the bone marrow. In addition to tumor cells invading the bone microenvironment, they express several transcription factors, which are involved in acquisition of an osteomimetic phenotype. This process of osteomimicry is essential for the anchorage and survival of cancer cells in the bone 
microenvironment. Targeting the bone metastatic process means targeting every step of the long path to the bone, beginning with the stem cell targets and the microenvironment in the primary tumor via the chemoattractant chemokines released by the bone niche (bone marrow) and the corresponding cancer cell receptors, through to the osteomimicry phenomenon and the tumor-stroma interactions in the bone niche.

Cancer stem cells can be targeted during this acquisition of self-renewal and migration ability (the epithelialmesenchymal transition process). In this respect, the most studied pathways are the WNT (Wingless-type), $\mathrm{SHH}$ (sonic hedgehog), NOTCH and PTEN (phosphatase and tensin homolog deleted on chromosome ten) pathways. In particular, the $\mathrm{SHH}$ pathway, highly expressed in cancer and mesenchymal stem cells, seems to be able to induce the bone modifications necessary to create the pre-metastatic niche [7]. The most interesting bone chemo-attractant chemokine pathways for therapeutic targeting are the CXCR4 (C-X-C chemokine receptor type 4)/SDF-1 (stromal cell-derived factor-1) pathway, the RANK (receptor activator of nuclear factor kappa B)/RANKL (receptor activator of nuclear factor kappa B ligand) pathway, the bone morphogenetic protein (BMP)/BMP receptor axis, and the integrins system. For example, it has been demonstrated that activation of the CXCR4/SDF-1 pathway not only regulates migration and homing of cancer cells to the bone but also regulates the adhesion, invasion and induced cytoskeletal rearrangement of cancer cells [8].

Finally, osteomimicry represents another potential therapeutic target to prevent or reduce the tumor burden in the bone. Several phenotypic modifications have been demonstrated in cancer cells during their homing in the bone niche. One of the most interesting 'osteomimicry processes' involves the RANK/RANKL/osteoprotegerin pathway. In each bone mineral unit (BMU), RANKL is produced by osteoblasts and stromal cells where it induces osteoclast activation and increased bone resorption through interaction with RANK receptors expressed by osteoclast precursors. Osteoprotegerin represents the natural antagonist of RANKL. The RANK/RANKL pathway is involved in tumor-induced osteoclastogenesis and osteolysis. Moreover, it has recently been demonstrated that many types of solid tumors express RANK both in primary sites and in metastatic bone [9]. Recent in vivo studies have demonstrated the association between RANK expression and cancer cell osteotropism. RANK is clearly associated with early bone metastasis formation in breast cancer [10]. These data allow us to consider this molecular pathway as one of the most exciting therapeutic targets for preventing and treating bone metastases.
Understanding fully this complexity represents a major challenge in anti-cancer research and a mandatory step towards the development of new drugs potentially able not only to reduce the consequences of metastatic bone lesions but also to target the pathogenic process from the 'bone preneoplastic niche' to the 'visceral preneoplastic niches' and to target bone metastases.

\section{Abbreviations}

CXCR4, C-X-C chemokine receptor type 4; RANK, receptor activator of nuclear factor kappa B; RANKL, receptor activator of nuclear factor kappa B ligand; SDF-1, stromal cell-derived factor-1.

\section{Author details}

'Department of Medical Oncology, University Campus Bio-Medico, Via Alvaro del Portillo 200, 00128, Rome, Italy. ${ }^{2}$ Department of Biomedical and Surgical Sciences, Unit of Diseases of Mineral Metabolism and the Bone, University of Verona, 37124, Verona, Italy.

\section{Published: 16 August 2011}

\section{References}

1. Clézardin P: Therapeutic targets for bone metastases in breast cancer. Breast Cancer Res 2011, 13:207.

2. Grimm J, Grimm W: The Complete Grimm's Fairy Tales. New York: Pantheon Books; 1944

3. Pardal R, Clarke MF, Morrison SJ: Applying the principles of stem-cell biology to cancer. Nat Rev Cancer 2003, 3:895-902.

4. Al-Hajj M, Wicha MS, Benito-Hernandez A, Morrison SJ, Clarke MF: Prospective identification of tumorigenic breast cancer cells. Proc Natl Acad Sci USA 2003, 100:3983-3988.

5. Kaplan RN, Riba RD, Zacharoulis S, Bramley AH, Vincent L, Costa C, MacDonald DD, Jin DK, Shido K, Kerns SA, Zhu Z, Hicklin D, Wu Y, Port JL, Altorki N, Port ER, Ruggero D, Shmelkov SV, Jensen KK, Rafii S, Lyden D: VEGFR1-positive haematopoietic bone marrow progenitors initiate the pre-metastatic niche. Nature 2005, 438:820-827.

6. Ramaswamy S, Perou CM: DNA microarrays in breast cancer: the promise of personalised medicine. Lancet 2003, 361:1576-1577.

7. Shimoyama A, Wada M, Ikeda F, Hata K, Matsubara T, Nifuji A, Noda M, Amano K, Yamaguchi A, Nishimura R, Yoneda T: Ihh/Gli2 signaling promotes osteoblast differentiation by regulating Runx2 expression and function. Mol Biol Cell 2007, 18:2411-2418.

8. Gerritsen ME, Soriano R, Yang S, Ingle G, Zlot C, Toy K, Winer J, Draksharapu A, Peale F, Wu TD, Williams PM: In silico data filtering to identify new angiogenesis targets from a large in vitro gene profiling data set. Physiol Genomics 2002, 10:13-20.

9. Santini D, Perrone G, Roato I, Godio L, Pantano F, Grasso D, Russo A, Vincenzi B, Fratto ME, Sabbatini R, Della Pepa C, Porta C, Del Conte A, Schiavon G, Berruti A, Tomasino RM, Papotti M, Papapietro N, Onetti Muda A, Denaro V, Tonini G: Expression pattern of receptor activator of NFKB [RANK] in a series of primary solid tumors and related bone metastases. J Cell Physiol 2011, 226:780-784

10. Santini D, Schiavon G, Vincenzi B, Gaeta L, Pantano F, Russo A, Ortega C, Porta C, Galluzzo S, Armento G, La Verde N, Caroti C, Treilleux I, Ruggiero A, Perrone G, Addeo R, Clezardin P, Muda AO, Tonini G: Receptor activator of NF-kB [RANK] expression in primary tumors associates with bone metastasis occurrence in breast cancer patients. PLoS One 2011, 6:e19234.

doi:10.1186/bcr2911

Cite this article as: Santini $D$, et al.: Targeting bone metastases starting from the preneoplastic niche: home sweet home. Breast Cancer Research 2011, 13:111. 